\title{
Single crystalline film scintillators based on the orthosilicate, perovskite and garnet compounds
}

\author{
Yu. Zorenko, V. Gorbenko, V. Savchyn, T. Voznyak, O. Sidletskiy, B. Grinyov, M. Nikl, J. A. Mares, \\ T. Martin, P.-A. Douissard
}

\begin{abstract}
This work reviews our R\&D of new types of scintillating screens based on the single crystalline films (SCF) of Lu,Y orthosilicate, perovskite and garnet compounds grown by the liquid phase epitaxy method. The scintillation and luminescent properties of the following types of SCF scintillators are considered in this work: i) Ce-doped SCF of Y,Lu-based orthosilicates and perovskites with the $\mathrm{Ce}^{3+}$ emission in the $325-600 \mathrm{~nm}$ and $360-370$ $\mathrm{nm}$ ranges with a decay time of 20-33 ns and 16-17 $\mathrm{ns}$, respectively; ii) Ce,Tb doped SCF of Y,Lu-based orthosilicates and perovskites with the simultaneous $\mathrm{Ce}^{3+}$ and $\mathrm{Tb}^{3+}$ emission in the blue or $\mathrm{UV}$ and green spectral ranges, respectively; iii) $\mathrm{Sc}^{3+}$ doped SCF of $\mathrm{Y}$ Lu-Al-garnets, emitting in the $290-400 \mathrm{~nm}$ range due to formation of the $S c_{Y, L u}$ and $S c_{A l}$ centers with a decay time of the order of hundreds of nanoseconds.
\end{abstract}

Index Terms - scintillating screens, luminescence, single crystalline films; liquid phase epitaxy, orthosilicates, perovskites, garnets, $\mathrm{Ce}^{3+}, \mathrm{Tb}^{3+}$ and $\mathrm{Sc}^{3+}$ dopants.

\section{INTRODUCTION}

During the last three decades the liquid phase epitaxy (LPE) proved to be a beneficial method for the development of luminescent materials based on single crystalline films (SCF) of oxide compounds, such as garnets, perovskites, sapphire, silicates and tungstates [1-15]. Apart from the laser media [1], cathodoluminescent screens [2-5] and $\alpha$ - and $\beta$-scintillators [68], developed in the 80-90th of the last century on the base of rare-earth doped $\mathrm{SCF}$ of $\mathrm{Y}_{3} \mathrm{Al}_{5} \mathrm{O}_{12}(\mathrm{YAG}), \mathrm{Lu}_{3} \mathrm{Al}_{5} \mathrm{O}_{12}(\mathrm{LuAG})$ and $\mathrm{Gd}_{3} \mathrm{Ga}_{5} \mathrm{O}_{12}$ (GGG) garnets, the application fields of such

Manuscript received November 3, 2011. This research was supported by NATO CBP.NUKR.CLG 984305 project, Czech Science Foundation (project No 202/08/0893) and Ministry of Education and Science of Ukraine (projects No SF-28 F).

Yuriy Zorenko with the Institute of Physics Kazimierz Wielki University in Bydgoszcz, 85-090 Bydgoszcz, Poland and with the Department of Electronics, Ivan Franko National University of Lviv, 79017 Lviv, Ukraine (corresponding author, phone: +48693330878 ; fax: +48523216166 ; e-mail: zorenko@ukw.edu.pl and zorenko@electronics.wups.lviv.ua).

Vitaliy Gorbenko, Taras Voznyak and Volodymyr Savchyn are with the Department of Electronics of Ivan Franko National University of Lviv, 79017 Lviv, Ukraine (e-mail: vhorbenko@inbox.ru; vtmesh@gmail.com; savchyn.lviv@mail.ru).

Oleg Sidletskiy and Boris Grinyov are with the Institute for Scintillation Materials, National Academy of Sciences of Ukraine, 61001 Kharkiv, Ukraine (e-mail: sidletskiy@isma.kharkov.ua and grinyov@isc.kharkov.com)

Martin Nikl and Jiri Mares are with the Institute of Physics AS CR, 162 53 Prague, Czech Republic (e-mail: nik1@,fzu.cz and amares@,fzu.cz)

Thierry Martin and Paul-Antoine Douissard are with European Synchrotron Radiation Facility (ESRF), ISDD/Detector Unit,, 6 rue Jules Horowitz, 38043 Grenoble, France (e-mail: tmartin@esrf.fr and paul_antoine.douissard@esrf.fr)
SCFs in the last decade are extended to X-ray visualization screens [9-15]. Namely, the fast development of microimaging techniques using $\mathrm{X}$-ray or synchrotron radiation for applications in microtomography in biology and medicine strongly demands scintillating screens with spatial resolution in the micron or even sub-micron ranges [12-15]. Recently for this task, X-ray image detectors based on SCF screens of YAG:Ce, GGG:Tb and LuAG:Eu garnets, microscope optics, low-noise CCD camera and operated with X-ray energies of 10-50 keV have been developed at ESRF $[11,12]$.

To increase further the spatial resolution of X-ray detectors in the sub- $\mu \mathrm{m}$ range the SCF scintillating screens emitting the blue or UV ranges [12] or scintillation screens with complex emission spectrum in blue/or UV and visible ranges $[13,14]$ are necessary. Registration of images in the blue or even in the UV range could increase the spatial resolution $\mathbf{R}$ of a detector according to the formula: $\mathbf{R} \sim \mathbf{0 . 6 1 * \lambda / N A}(\mathbf{1})$, where $\lambda$ is the emission wavelength, NA is the numerical aperture of the optics [12]. Significant improvement of image contrast can also be reached by the application of SCF with thickness below $10 \mu \mathrm{m}$, optics with NA 0.5 and the blue or UV emission of such screens [15].

The $\mathrm{Lu}_{3} \mathrm{Al}_{5} \mathrm{O}_{12}$ garnet (LuAG) is excellent host to prepare such SCF scintillators due to high ability of X-ray absorption, which is proportional to $\boldsymbol{\rho Z}_{\text {eff }}{ }^{4}\left(\boldsymbol{\rho}=6.7 \mathrm{~g} / \mathrm{cm}^{3}\right.$ is the density and $\mathbf{Z}_{\text {eff }}=61$ is the effective atomic number) [9-12]. Due to elimination of $\mathrm{Lu}_{\mathrm{Al}}$ antisite defects and low concentration of oxygen vacancies in LPE grown $\mathrm{SCF}$, the $\mathrm{Ce}^{3+}$ doped LuAG SCF scintillators possess significant advantages with respect to their SC counterparts [16, 17], such as faster scintillation response and better energy resolution (FWHM) [18].

$\mathrm{Lu}_{2} \mathrm{SiO}_{5}$ (LSO) orthosilicates and $\mathrm{LuAlO}_{3}(\mathrm{LuAP})$ perovskite hosts have significantly higher density $\left(\rho=7.4\right.$ and $\left.8.34 \mathrm{~g} / \mathrm{cm}^{3}\right)$ and effective atomic number $\left(Z_{\text {eff }}=66\right.$ and 64.9 , respectively) $[8$, 13-15] as compared to the previously used YAG $\left(\rho=4.6 \mathrm{~g} / \mathrm{cm}^{3}\right.$, $\left.Z_{\text {eff }}=29\right)$ and LuAG based compounds [9-12]. Single crystals (SC) of LSO:Ce and ( $\mathrm{LuY})_{2} \mathrm{SiO}_{5}: \mathrm{Ce}$ (LYSO:Ce) are the wellknown scintillators for Positron Emission Tomography (PET) [8]. $\mathrm{Ce}^{3+}$ doped $\mathrm{LuAlO}_{3}$ (LuAP) and (LuY)AlO 3 (LuYAP) perovskites are also very efficient oxide scintillators [8]. These matrices can thus serve as excellent hosts to create SCF scintillators emitting in the visible and $U V$ ranges $[12,15]$.

The growth of LSO:Ce and $\left(\mathrm{Lu}_{1-\mathrm{x}} \mathrm{Gd}_{\mathrm{x}}\right)_{2} \mathrm{SiO}_{5}$ : $\mathrm{Ce}$ (LGSO:Ce) SCF scintillators onto LSO substrates by LPE method have been reported by some of us in $[19,20]$. The growth of $\mathrm{Lu}_{2} \mathrm{SiO}_{5}: \mathrm{Tb}$ and $\mathrm{Lu}_{2} \mathrm{SiO}_{5}$ :Tb,Ce SCFs onto YbSO and LYSO substrates by LPE methods has been also reported in works [13, 14]. 
Testing the $\mathrm{Lu}_{2} \mathrm{SiO}_{5}: \mathrm{Tb}$ and $\mathrm{Lu}_{2} \mathrm{SiO}_{5}: \mathrm{Tb}, \mathrm{Ce} \mathrm{SCF}$ screens for visualization of X-ray image was performed as well [14]. The result of works $[13,14]$ shows that the $\mathrm{Lu}_{2} \mathrm{SiO}_{5}$ :Tb, Ce SCF screens with simultaneous emission in the blue and green ranges have excellent spatial resolution of X-ray image up to $0.8 \mu \mathrm{m}$ FWHM [14]. The double epitaxial structures consisting of two LSO:Tb and LYSO:Ce SCF were also grown by the LPE method and tested for visualization of X-ray images [14].

Recently, the growth of YAP:Ce and LuAP:Ce SCF from $\mathrm{PbO}$ flux has been reported by us in several works [21-23]. Both types of SCF films were of very good structural and optical quality $[22,23]$. We also performed preliminary testing the LuAP:Ce SCF screens for visualization of X-ray image [15]. The scintillation and luminescent properties of these films were studied as well [22-25]. Strong decrease (more than three times) of the LY of YAP:Ce and LuAP:Ce SCF, with respect to the LY of their SC analogues was noted due to the influence of $\mathrm{Pb}$-based flux-related centers on the $\mathrm{Ce}^{3+}$ luminescence in perovskite hosts [24, 25]. This fact decreases the application possibilities of such a type of SCF scintillators.

In this work, we continue the investigations of growth processes of scintillating screens based on the SCF of orthosilicates, perovskites and garnets by LPE methods. We focus on the growth of $\mathrm{Ce}$ and $\mathrm{Ce}, \mathrm{Tb}$ doped (Y,Lu)SO and (Y,Lu)AP SCFs and $\mathrm{Sc}^{3+}$ doped LuAG SCF onto substrates prepared from undoped YSO, YAP and YAG crystals. The YSO, YAP and YAG hosts have the close crystal structure to that of LSO, LuAP and LuAG, but YSO, YAP and YAG substrates are significantly cheaper.

In this work, we grew several sets of the $\mathrm{Ce}$ and $\mathrm{Ce}, \mathrm{Tb}$ doped (L,Y)SO and (Y,Lu)AP and $\mathrm{Sc}^{3+}$ doped LuAG SCF's onto the undoped YSO, YAP and YAG substrates, respectively. We also studied their scintillation and luminescent properties in comparison with those of LSO:Ce, $(\mathrm{LuY})_{2} \mathrm{SiO}_{5}: \mathrm{Ce}$ (LYSO:Ce), YAP:Ce, LuYAP:Ce and LuAG:Sc SC, prepared by the Czochralski method.

\section{GROWTH OF SCF SCINTILLATORS AND EXPERIMENTAL TECHNIQUES}

The series of the $\mathrm{Ce}, \mathrm{Ce}, \mathrm{Tb}$ and Sc-doped (LuY)SO, (LuY)AP and (Lu,Y)AG SCFs were grown in LOM of Lviv University and the ESRF by the LPE methods onto undoped YSO, YAP and YAG substrates, respectively, with diameters ranging from $5 \mathrm{~mm}$ to $25 \mathrm{~mm}$, from super-cooled melt-solution (MS) based on the $\mathrm{PbO}-\mathrm{B}_{2} \mathrm{O}_{3}$ flux at relatively low temperatures $\left(950-1100^{\circ} \mathrm{C}\right)$ as compared to Czochralski-grown SC analogues $\left(\sim 2000-2100{ }^{\circ} \mathrm{C}\right)$. The thickness of the SCF scintillators was varied from 12.2 to $62 \mu \mathrm{m}$. It is very important to note that we did not use any additional doping to reduce the significant differences in the lattice constants of the LSO, LuAP and LuAG based SCF and the YSO, YAP and YAG substrates which are of about 2.1, 1.4 and $1.0 \%$, respectively $[20,21,26]$. As a result, we can confirm in this work that the SCFs of LSO, LuAP and LuAG compounds can be grown onto significantly cheaper YSO, YAP and YAG substrates.

The low growth temperature of SCF results in absence or substantial decrease of the concentration of main types of defects, such as antisite defects and oxygen vacancies, in ( $\mathrm{Lu}, \mathrm{Y}) \mathrm{SO}$, (LuY)AP and (Lu,Y)AG SCFs in comparison with bulk SC analogues [16, 17, 19, 20, 22, 23, 27]. On the other hand, flux components are introduced in the SCF and strongly influence their luminescence and scintillation properties $[19,20,24,25$, 28]. Usually, the SCFs prepared from the PbO-based flux, can contain lead ions preferably in the $\mathrm{Pb}^{2+}$ charge state. Since the $\mathrm{PbO}$-based melt dissolves the Pt-crucible, Pt ions can also be introduced in the orthosilicate, perovskite or garnet lattices. As a consequence, various locally non-compensated lattice defects can be created, what may result in the decrease of the scintillation efficiency and LY of SCF scintillators [19, 20, 25, 28].

The LY of the mentioned SCF can be optimized mainly by means of optimization of activator content in MS [19, 20, 25, 26]. Taking into account very low segregation coefficient of $\mathrm{Ce}^{3+}$ ions in (Y,Lu)SO SCFs (of about $\left.0.005[19,20]\right)$ and (Y,Lu)AP SCFs (of about $0.01[21,25]$ ), we keep very large content of 20-25\% mole of $\mathrm{CeO}_{2}$ activated oxide in MS at the crystallization of the mentioned SCF onto YSO and YAP substrates. Contrary to large $\mathrm{Ce}^{3+}$ ions $(1.01 \AA$ in six-fold coordination [29]), the smaller $\mathrm{Tb}^{3+}$ ions $(0.92 \AA)$ has significantly larger segregation coefficient both in $(\mathrm{Y}, \mathrm{Lu}) \mathrm{SO}$ SCFs (of about 0.6 [20]) and (Y,Lu)AP SCF (of about 0.7 [21]). The segregation coefficient of Sc ions in LuAG SCF is relatively large (of about 0.4 ) in a concentration range of $0.1-5$ at. \% [15]. At the same time, the concentration of different impurities in the SCF depends not only on the content of activated oxides in MS, but is also strongly influenced by the SCF growth temperature. Namely, the concentrations of dopants as well as $\mathrm{Pb}$ and $\mathrm{Pt}$ impurities increase with decreasing the growth temperature and vice versa [19-21, 25, 26]. Thus, we have used relatively high growth temperatures above $1000{ }^{\circ} \mathrm{C}$ for SCF preparation.

The content of different dopants in SCF under study was determined using JEOL JXA-8612 MX electron microscope and presented in Table 1 for different series of SCF scintillators.

To estimate scintillation efficiency of the developed UV emitting SCF scintillators the relative LY measurements of all the series of SCF samples were performed in comparison with the standard samples of LSO:Ce, LYSO:Ce, YAP:Ce, $\mathrm{Lu}_{0.3} \mathrm{Y}_{0.7} \mathrm{AP}: \mathrm{Ce}$, LuAG:Sc, YAG:Sc and YAG:Ce bulk SC scintillators, grown by Czochralski $(\mathrm{Cz})$ or horizontal direct crystallization (HDC) methods, as well as with the standard sample of YAG:Ce SCF under excitation by $\alpha$-particles of $\mathrm{Pu}^{239}(5.15 \mathrm{MeV})$ radioisotope which have penetration depth of about of 10-12 $\mu \mathrm{m}$ in the studied materials (see Table 1). Under excitation by the mentioned source the LY of YAG:Ce SCF standard sample was 16600 photon/MeV. LY of the reference LSO:Ce, LYSO:Ce and YAP:Ce SC under gamma excitation $\left(662 \mathrm{keV},{ }^{137} \mathrm{Cs}\right)$ was 7380 , 16560 and 21030 photon/MeV, respectively.

For LY measurements of Ce-dopede SCF scintillators we have used detector based on FEU-110 photomultipliers which have the maximum sensitivity in the 440-450 $\mathrm{nm}$ range and multi-channel single-photon counting systems working with a shaping time of $0.5 \mu \mathrm{s}$. For $\mathrm{Tb}^{3+}$ doped $\mathrm{SCF}$ we perform the measurements of LY of luminescence under excitation by X-ray 
TABLE 1

Relative LY of the best samples in series of Ce and Tb doped (Y,Lu)SO and (Y,Lu)AP and Sc-doped (Lu,Y)AG based SCF scintillators in comparison with standard bulk SC analogues and standard YAG:Ce SCF sample (all of them are indicated by $\left.{ }^{*}\right)$ under excitation by $\alpha$-particles of $\mathrm{Pu}^{239}$ sources $(5.15 \mathrm{MeV})$ and X-ray excitation $\left(\mathrm{Cu}_{\mathrm{K} \alpha}\right)$ at $300 \mathrm{~K} . \mathrm{n} . \mathrm{m}$. - not measured.

\begin{tabular}{|c|c|c|c|c|c|}
\hline $\begin{array}{c}\text { Type of } \\
\text { scintillator }\end{array}$ & $\begin{array}{l}\mathrm{Ce} / \mathrm{Tb} / \mathrm{Sc} \\
\text { content in } \\
\mathrm{SCF}, \text { at.\% }\end{array}$ & $\begin{array}{c}\text { Emission } \\
\text { wave- } \\
\text { length, } \mathrm{nm}\end{array}$ & $\begin{array}{c}\text { Decay time, } \\
\text { (to } 1 / \mathrm{e} \\
\text { level), ns }\end{array}$ & \begin{tabular}{|c|}
$\mathrm{LY}$ under \\
excitation by \\
$\mathrm{Pu}^{239}$ source
\end{tabular} & \begin{tabular}{|c|} 
LY under \\
X-ray \\
excitation
\end{tabular} \\
\hline YSO:Ce SCF & $\sim 0.075$ & 430 & 15.9 & $50-60$ & \\
\hline LSO:Ce SCF & 0.09 & 430 & 19.6 & $52-74$ & \\
\hline LSO:Ce,Tb SCF & $0.08 / 0.93$ & $430 ; 544$ & $\sim 15 / \sim \mu \mathrm{s}$ & 48 & 140 \\
\hline LSO:Tb SCF & 0.9 & 544 & $\sim \mu \mathrm{s}$ & n. $m$. & 130 \\
\hline LSO:Ce SC & $\sim 0.2$ & 420 & 40.5 & 100 & \\
\hline LYSO:Ce SC & n. m. & 420 & n. m. & 282 & \\
\hline YAG:Ce SCF* & 0.04 & 530 & $\sim 80$ & 250 & \\
\hline YAG:Ce SC* & n. m. & $\sim 550$ & $\sim 92$ & 350 & 100 \\
\hline YAP:Ce SCF & 0.08 & 369 & 13.7 & 25.5 & \\
\hline$Y_{0.4} \mathrm{Lu}_{0.6} \mathrm{AP}: \mathrm{Ce} \mathrm{SCF}$ & 0.04 & 373 & 16.0 & 10.2 & \\
\hline LuAP:Ce SCF & 0.03 & 378 & 16.8 & 7.65 & \\
\hline LuAP:Ce,Tb SCF & 2.4 & $358 ; 544$ & n. $m$. & n. $m$. & 144 \\
\hline YAP:Ce SC* & $\sim 0.1$ & 366 & 16.2 & 100 & \\
\hline $\mathrm{Lu}_{0.3} \mathrm{Y}_{0.7} \mathrm{AG}: \mathrm{Ce} \mathrm{SC} *$ & $\sim 0.1$ & 375 & 18.1 & 56.3 & \\
\hline LuAG :Sc SCF & 1.0 & 282 & $\sim 300$ & 46.2 & \\
\hline (LuY)AG :Sc SCF & 1.85 & 314 & $\sim 650$ & 48.2 & \\
\hline YAG :Sc SC* & 0.39 & 314 & $\sim 580$ & 45.9 & \\
\hline LuAG:Sc SC HDC* & 0.75 & 285 & n. $m$. & 60.0 & \\
\hline LuAG :Sc SC Cz* & 0.11 & 290 & 1330 & 21.8 & \\
\hline
\end{tabular}

( $\mathrm{Cu}$ anode operated at $20 \mathrm{kV}$ and $40 \mathrm{~mA}$ ). The emitted radiation was filtered with a 25 thick $\mathrm{Cu}$ foil. The light intensity was recorded with a 4x-microscopic objective and a Sensicam CCD. Measurements were corrected for the absorption efficiency of the scintillator and the quantum efficiency of the CCD.

We have also performed the comparative LY measurements of chosen SCF samples under X-ray $\left(\mathrm{Cu}_{\mathrm{Ka}}\right.$, $\mathrm{E}_{\text {eff }}=8 \mathrm{keV}$ )) excitation with taking into account the absorption ability of SCF scintillators which is proportional to $\mathbf{h} \rho \mathbf{Z}^{\mathbf{4}}$, where $\mathrm{h}$ is the thickness of SCF, $\boldsymbol{\rho}$ and $\mathbf{Z}^{4}$ are the density and effective atomic number of scintillator hosts. The results of LY measurements are presented in Table 1.

Luminescent properties of SCF under study were characterized by means of cathodoluminescence (CL) spectra under pulsed e-beam excitation (a pulse duration of $2 \mu$ s and a frequency of 30-3 Hz) with electron energy of $9 \mathrm{keV}$ and a beam current of $100 \mu \mathrm{A}$. The emission spectra were corrected for the spectral dependence of the detection part consisting of DMR-4 monochromator and FEU-106 photomultiplier.

The luminescence decay kinetics was measured at $300 \mathrm{~K}$ in the 100-190 ns time interval under excitation by synchrotron radiation (SR) with pulse duration of $0.126 \mathrm{~ns}$ at the Superlumi experimental station in HASYLAB, DESY.

\section{LUMINESCENCE SPECTRA AND LIGHT YIELD OF CE AND CE,TB DOPED (LU,Y) $)_{2} \mathrm{SiO}_{5} \mathrm{SCF}_{\mathrm{SCINTILLATORS}}$}

The CL spectra of YSO:Ce and LSO:Ce SCF grown at maximal $\mathrm{CeO}_{2}$ content of $20-25 \%$ in MS are shown in Fig.1a. The dominant doublet emission band peaked around $430 \mathrm{~nm}$ in the spectra both of YSO:Ce and LSO:Ce SCFs is caused by the $\mathrm{Ce}^{3+}$ ions in $\mathrm{Y} 1$ and Lu1 positions with seven oxygen ligands (Ce1 centers). At the same time, enhancement of these emissions at the long-wavelength side is due to emission of $\mathrm{Ce}^{3+}$ ions in the $\mathrm{Y} 2$ and $\mathrm{Lu} 2$ positions with six oxygen ligands ( $\mathrm{Ce} 2$ centers).
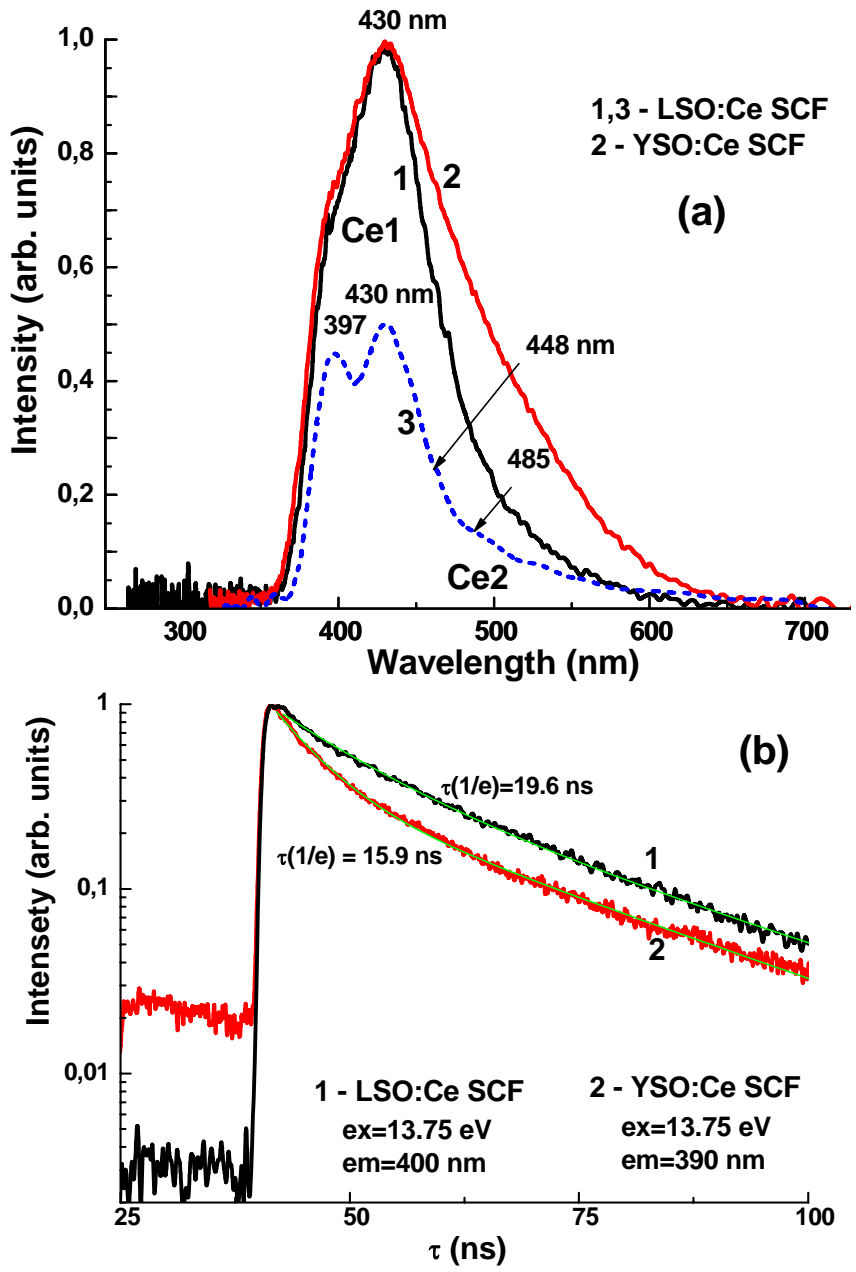

Fig.1. (a) - normalized CL spectra of LSO:Ce SCF (1) and YSO:Ce SCF (2) at $300 \mathrm{~K}(1,2)$ and $77 \mathrm{~K}(3)$; (b) - decay kinetics of $\mathrm{Ce}^{3+}$ luminescence at 390-400 nm in LSO:Ce SCF (1) and YSO:Ce SCF (2) under excitation by SR with an energy of $13.75 \mathrm{eV}$ above band gap of YSO and LSO hosts. The parameters of approximation of corresponding decay curves $\mathrm{I}=0.48 \exp (-$ $\mathrm{t} / 9.45 \mathrm{~ns})+0.40 \exp (-\mathrm{t} / 27.4 \mathrm{~ns})(\mathrm{LSO}: \mathrm{Ce} \mathrm{SCF})$ and $\mathrm{I}=0.58 \exp (-\mathrm{t} / 5.11 \mathrm{~ns})+$ $0.34 \exp (-\mathrm{t} / 24.7 \mathrm{~ns})$ (YSO:Ce SCF) are given by the green solid lines

The structure of the luminescence of $\mathrm{Ce} 1$ and $\mathrm{Ce} 2$ centers due to the radiative transitions from $5 \mathrm{~d}_{1}$ levels to ${ }^{2} \mathrm{~F}_{5 / 2,7 / 2}$ levels of the $\mathrm{Ce}^{3+}$ ground state is well resolved in the CL spectra of YSO:Ce and LSO:Ce SCF at $77 \mathrm{~K}$ (see curve 3 in Fig.1a for LSO:Ce SCF with the 397, $430 \mathrm{~nm}$ and 448, 485 the nm subbands, respectively). As the temperature increases from 77 to 300 $\mathrm{K}$, the intensity of the $\mathrm{Ce}^{3+}$ emission in (LuY)SO:Ce SCFs increases by a factor of two (Fig.1a, curve 3 and 1, respectively). We have also compare the decay kinetics of the $\mathrm{Ce}^{3+}$ luminescence in YSO:Ce and LSO:Ce SCFs under excitation by SR with an energy of $13.75 \mathrm{eV}$ above band gap of YSO and LSO hosts (Fig.1b). Due to very high absorption coefficient of YSO and LSO matrixes in this range, the depth of penetration of excitation beam is the same as in the case of both SCF and usually does not exceed a few microns, i.e. all the excitation energy is deposited only in SCF. Both decay kinetics of the $\mathrm{Ce}^{3+}$ luminescence in LSO:Ce and YSO:Ce SCF (Fig.1b, curves 1 and 2, respectively) are visibly nonexponential. Therefore, we estimate the decay times $\tau(1 / \mathrm{e})$ of the corresponding decay curves in YSO:Ce and LSO:Ce SCFs which are equal to $15.9 \mathrm{~ns}$ and $19.6 \mathrm{~ns}$, respectively. 

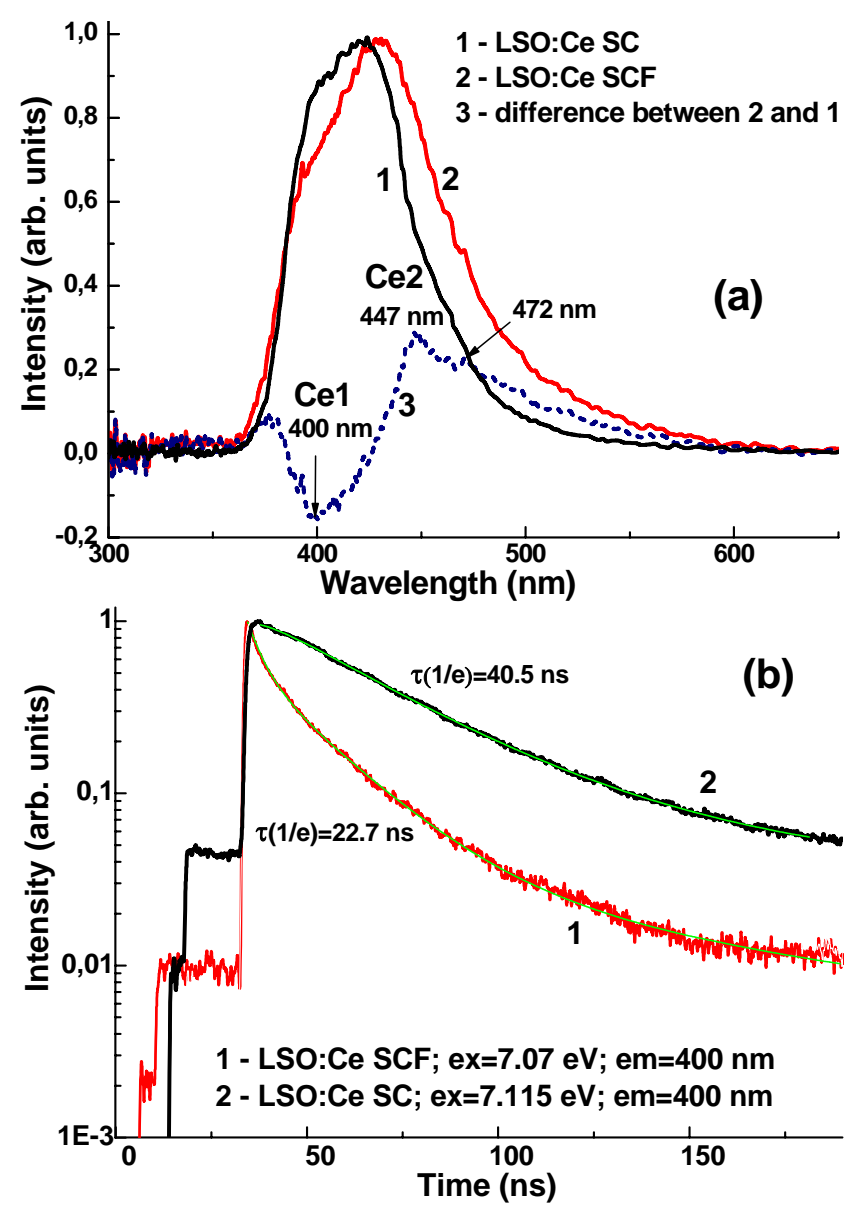

Fig.2. (a) - normalized CL spectra of LSO:Ce SCF (1) and SC (2). Curve 3 show the difference between the CL spectra of LSO:Ce SCF and SC; (b) - decay kinetics of $\mathrm{Ce}^{3+}$ luminescence at $400 \mathrm{~nm}$ in LSO:Ce SCF (1) and SC (2) under excitation with an energy of 7.07-7.15 eV. The parameters of approximation of corresponding decay curves $I=0.44 \exp (-\mathrm{t} / 3.7 \mathrm{~ns})+0.51 \exp (-\mathrm{t} / 19.2 \mathrm{~ns})+0.03$ $\exp (-t / 106.8 \mathrm{~ns})(\mathrm{LSO}: \mathrm{Ce} \mathrm{SCF})$ and $\mathrm{I}=-0.12 \exp (-\mathrm{t} / 5.11 \mathrm{~ns})+0.99 \exp (-\mathrm{t} / 31.6 \mathrm{~ns})$ $+0.07 \exp (-\mathrm{t} / 225.3 \mathrm{~ns})(\mathrm{LSO}: \mathrm{Ce} \mathrm{SC})$ are given by the green solid lines. $\mathrm{T}=300 \mathrm{~K}$.

The emission spectra of YSO:Ce and LSO:Ce SCFs (Fig.2a, curve 2) also show higher intensity in the longwavelength range with respect to the spectrum of SC analogues (Fig.2a, curve 1) where $\mathrm{Ce} 2$ center (six oxygen ligands) emits. As one can see from Fig.2, the CL spectra of LSO:Ce SCF in comparison with SC show lower intensity of emission in the band peaked at $400 \mathrm{~nm}$, related to the luminescence of $\mathrm{Ce} 1$ centers, and larger intensity of emission in the sub-bands peaked at 447 and $472 \mathrm{~nm}$ related to the luminescence of $\mathrm{Ce} 2$ centers in LSO matrix (Fig.2b, curve 3).

The decay curves in YSO:Ce and LSO:Ce SCFs are also visibly non-exponential and faster with respect to those in the SC counterpart (Fig.2b, curve 1 and 2, respectively). Such an acceleration of the decay of the $\mathrm{Ce}^{3+}$ luminescence in YSO:Ce and LSO:Ce SCF may indicate the energy transfer away from the excited states of $\mathrm{Ce}^{3+}$ ions and can partly explain the obtained lower scintillation efficiency of PbO-grown (Y, Lu)SO:Ce SCFs (Table 1). We assume that the energy transfer can occur from $\mathrm{Ce}^{3+}$ ions to some $\mathrm{Pb}^{2+}$-based centers. However, the nature of the latter centers is not clear and needs further investigations.

The above mentioned results also show that the $\mathrm{Pb}^{2+}$ ions can participate in the excitation of the $\mathrm{Ce}^{3+}$ luminescence in YSO:Ce and LSO:Ce SCF under high-energy excitation due to the overlap of the emission bands of $\mathrm{Pb} 1$ center and partly of the emission bands of $\mathrm{Pb} 2$ centers peaked at the 365-350 $\mathrm{nm}$ and 445-435 $\mathrm{nm}$ ranges, respectively [19, 20], with absorption bands of $\mathrm{Ce}^{3+}$ ions both in $\mathrm{Y} 1 / \mathrm{Lu} 1$ and $\mathrm{Y} 2 / \mathrm{Lu} 2$ positions, located in $320-400 \mathrm{~nm}$ range [30, 31]. Specifically, the high-energy wings of the $\mathrm{Pb}^{2+}$ emission spectra in YSO:Ce and LSO:Ce SCF can be strongly re-absorbed by $\mathrm{Ce} 1$ and $\mathrm{Ce} 2$ bands peaked approximately at $365 \mathrm{~nm}$ and $375 \mathrm{~nm}$ in YSO and LSO host, respectively [30, 31]. But under high energy excitation, apart from energy transfer between the $\mathrm{Pb}^{2+}$ and $\mathrm{Ce}^{3+}$ ions in $\mathrm{Y} 1 / \mathrm{Lu} 1$ and $\mathrm{Y} 2 / \mathrm{Lu} 2$ positions of $\mathrm{YSO}$ and $\mathrm{LSO}$ hosts, the effective transfer from excited state of $\mathrm{Ce}^{3+}$ ions to some $\mathrm{Pb}^{2+}$-based centers may also occur in YSO:Ce and LSO:Ce SCFs. This can be an additional reason for the lower LY of these SCFs with respect to that of SC analogues.

The LY of YSO:Ce and LSO:Ce SCFs was investigated under $\alpha$-particles of $\mathrm{Pu}^{239}$ sources depending on the $\mathrm{CeO}_{2}$ activator content in MS in the 5-25\% mole range. The $\mathrm{LY}$ of the both types of SCF increases with increasing the $\mathrm{CeO}_{2}$ content in MS up to maximum possible concentration of this oxide in the 20-25 mole \% range. Meanwhile, the LY of YSO:Ce and LSO:Ce SCF strongly depends also on SCF growth temperature: when the growth temperature decreases it also decreases and vice versa. Such a dependence of LY on the growth temperature reflects the respective change of the value of $\mathrm{Ce} / \mathrm{Pb}$ ions ratio in SCFs due to different dependence of the segregation coefficient of $\mathrm{Ce}^{3+}$ and $\mathrm{Pb}^{2+}$ ions on the growth temperature. The LY value of the best YSO:Ce and LSO:Ce SCF samples reaches only $18-26 \%$ of that of the high-quality standard LYSO:Ce SC sample (see Table 1). The lower LY of (Y,Lu)SO:Ce SCFs with respect to the best SC analogues is due to the strong quenching influence of $\mathrm{Pb}^{2+}$ centers on the $\mathrm{Ce}^{3+}$ luminescence in SCFs of all oxide compounds [19, 20, 24, 28].

The problem with the low LY of $\mathrm{Ce}^{3+}$ doped $(\mathrm{Y}, \mathrm{Lu}) \mathrm{SO}$ SCF can be partly eliminated by doping these SCF with other $\mathrm{RE}$ ions with significantly larger segregation coefficients in the condition of the LPE crystallization. For this purpose we have grown and investigated the luminescent properties of $\mathrm{Ce}, \mathrm{Tb}$ doped LSO SCF. Smaller Tb ${ }^{3+}$ ions $(0.92 \AA)$ have significantly larger segregation coefficient (of about 0.6) in (Y,Lu)SO SCFs respect to $\mathrm{Ce}^{3+}$ ions (of about 0.005) [20]. We note that due to the relatively long registration time interval (up to $10 \mathrm{~ms}$ ) in the case of X-ray excited scintillating screens [12] we can use RE activators with the dominant $\mathrm{f}-\mathrm{f}$ luminescence with decay times in the range of milliseconds $\left(\mathrm{Tb}^{3+}, \mathrm{Eu}^{3+}\right)$.

The CL spectra of LSO:Ce,Tb SCF (Fig.3) present the superposition of the fast $\mathrm{Ce}^{3+}$ luminescence in the UV range and slow green emission in the visible range, related to the ${ }^{5} \mathrm{D}_{4}{ }^{7} \mathrm{~F}_{\mathrm{x}}$ transition of $\mathrm{Tb}^{3+}$ ions. The green $\mathrm{Tb}^{3+}$ luminescence is dominating in the CL spectra of LSO:Ce,Tb SCF recorded with a delay time of $40 \mu \mathrm{s}$ with respect to the excitation electron pulse.

In comparison with the CL spectra of LSO:Ce SCF (Fig.1), the intensity of the $\mathrm{Ce}^{3+}$ luminescence in LSO:Ce,Tb SCF (Fig.3) is strongly reduced. Most probably, the effective $\mathrm{Ce}^{3+} \rightarrow \mathrm{Tb}^{3+}$ energy transfer is realized in LSO:Ce,Tb SCF due to the overlap of $\mathrm{Ce} 1$ emission and ${ }^{5} \mathrm{D}_{3}{ }^{-}{ }^{7} \mathrm{~F}_{6} \mathrm{~Tb}^{3+}$ emission around $380 \mathrm{~nm}$, but this assumption needs the additional experimental confirmation. The $\mathrm{Tb}^{3+}$ co-doping also leads to strong decrease of scintillation LY of LSO:Ce,Tb SCF, 


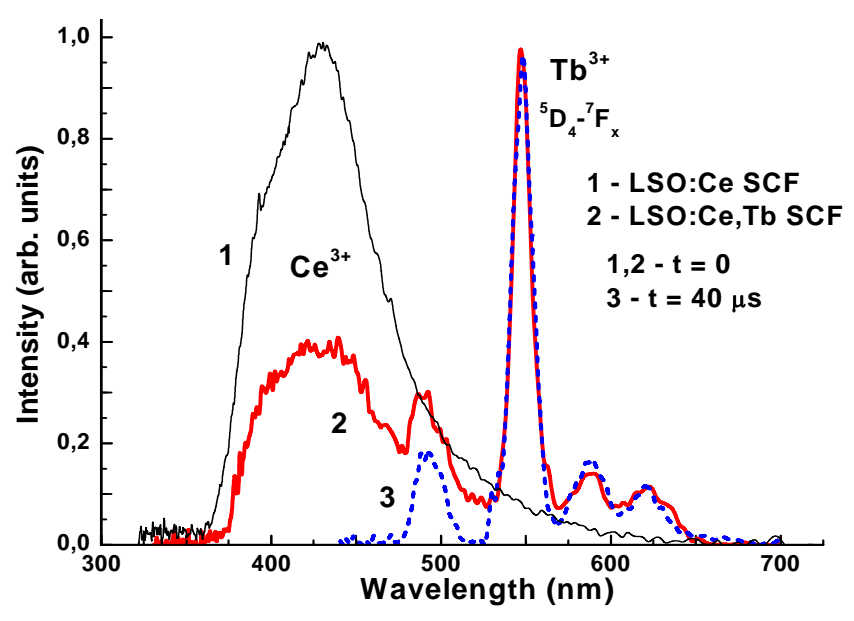

Fig.3. Normalized CL spectra of LSO:Ce SCF (1) and LSO:Ce,Tb $(2,3)$ SCF at delays $\Delta \mathrm{t}=0(2)$ and $\Delta \mathrm{t}=40 \mu \mathrm{s}(3)$.

measured in a time interval of $0.5 \mu$ s (see Table 1) mainly due to the decrease of the contribution of the fast $\mathrm{Ce}^{3+}$ luminescence. But under X-ray excitation the total LY of $\mathrm{Tb}^{3+}$ doped LSO SCF is very high (Table 1) due to strong contribution of the $\mathrm{Tb}^{3+}$ luminescence and effective $\mathrm{Ce}-\mathrm{Tb}$ energy transfer. Specifically, the LY of the X-ray excited luminescence is by $40-45 \%$ larger than that for high-quality YAG:Ce SC standard sample (Table 1).

Thus, the Ce-Tb co-doping is very effective method for creation of scintillating screens based on (YLu)SO orthosilicates with high LY of X-ray excited luminescence. Such type of screens can simultaneously emit in the blue and green range (Fig.3) and the contribution of emissions in the mentioned ranges can be tuned by the changing the ratio of $\mathrm{Ce} / \mathrm{Tb}$ ions in SCF using different temperatures of their crystallization.

\section{LUMINESCENCE SPECTRA AND LIGHT YIELD OF CE AND CE,TB DOPED (LU,Y)ALO ${ }_{3}$ SCF SCINTILLATORS}

The CL spectra of YAP:Ce and LuAP:Ce SCF (Fig.4a, curves 1 and 2, respectively) show intensive emission bands in the UV $(320-450 \mathrm{~nm})$ range peaked at 369 and $378 \mathrm{~nm}$ respectively, related to the $5 \mathrm{~d}^{1} \rightarrow 4 \mathrm{f}\left({ }^{2} \mathrm{~F}_{5 / 2,7 / 2}\right)$ transitions of $\mathrm{Ce}^{3+}$ ions [21-23]. It is important to note that the short-wavelength part of the $\mathrm{Ce}^{3+}$ emission band in YAP:Ce and LuAP:Ce SCF grown from the PbO-based flux can be partly distorted by the UV emission band of $\mathrm{Pb}^{2+}$ ions peaked at $340 \mathrm{~nm}[24,25]$ (Fig.4a). Other lowintensity complex emission band in YAP:Ce and LuAP:Ce $\mathrm{SCF}$, related to the luminescence of excitons localized around of $\mathrm{Pb}^{2+}$ based centers, is located in the visible range with maximum approximately at 610 and $550 \mathrm{~nm}$, respectively (Fig.4a). The intensity of the latter bands significantly increases with raising the total $\mathrm{Pb}$ conent in these SCFs [24, 25].

As can be seen from Table 1, the LY of YAP:Ce and especially of LuAP:Ce SCF scintillators, grown even at the optimal $10-20 \mathrm{~mol} \% \mathrm{CeO}_{2}$ content in the $\mathrm{MS}$, is significantly lower (by 3.9 and 7.6 times, respectively) than that of their YAP:Ce and (Y-Lu)AP:Ce bulk SC analogues. The main reason for such a low LY of $(\mathrm{Lu}, \mathrm{Y}) \mathrm{AP}$ :Ce SCF scintillators is the large incorporation of $\mathrm{Pb}^{2+}$ ions in SCF of perovskites due to relatively large volume of cuboctahedral position in perovskite
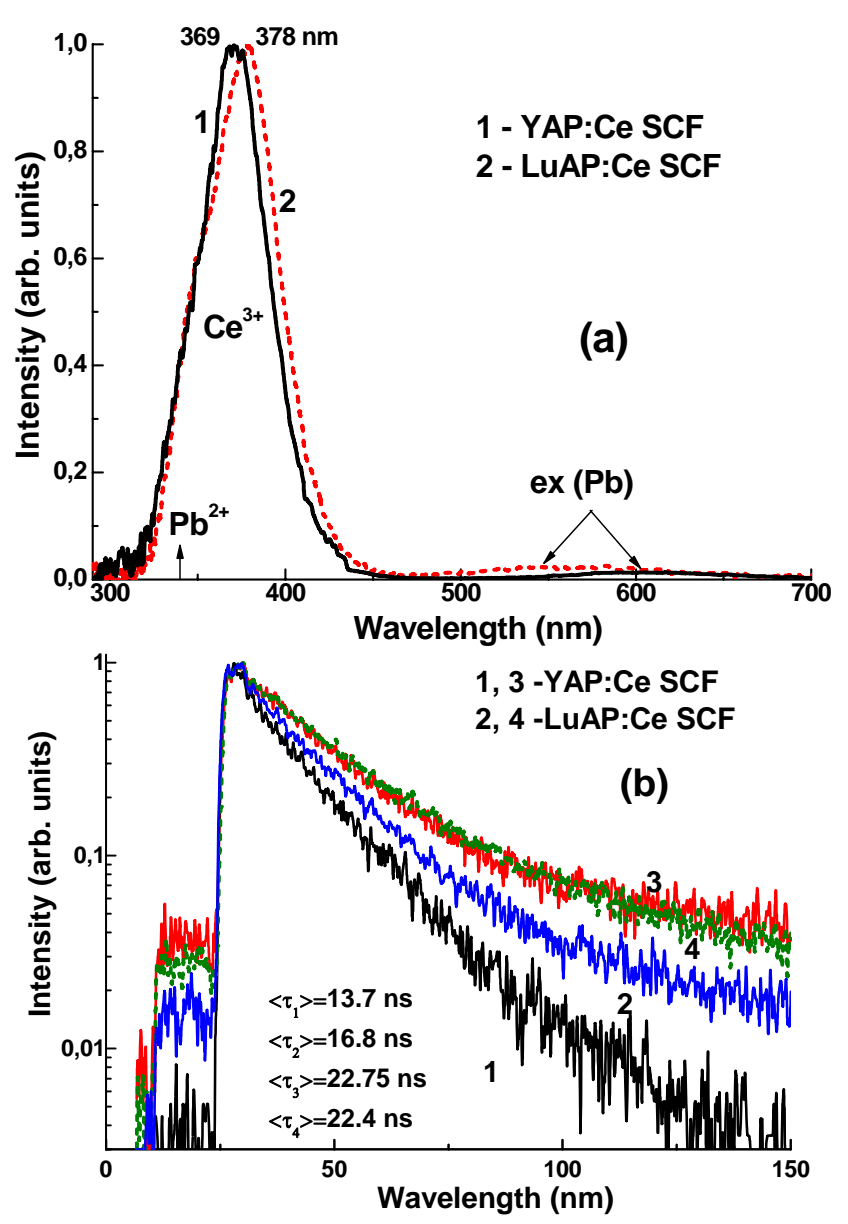

Fig.4. (a) - normalized CL spectra of YAP:Ce (1) and LuAP:Ce (2) SCF at $300 \mathrm{~K}$; (b) - decay kinetics of $\mathrm{Ce}^{3+}$ luminescence at 370-375 nm in YAP:Ce $(1,3)$ and LuAP:Ce $(2,4)$ SCFs under excitation by SR radiation in the $\mathrm{Ce}^{3+}$ absorption band at $295 \mathrm{~nm}$ (curves 1,2) and the exciton range at 145-160 nm (curves 3, 4) at $300 \mathrm{~K}$

lattice where $\mathrm{Pb}^{2+}$ ions are localized. We also note that the LY of (Y-Lu)AP:Ce SCF systematically decreases with increasing the Lu content up to a value of about $8 \%$ for LuAP:Ce SCF as compared to that of YAP:Ce SC. This effect can be explained by easier incorporation of $\mathrm{Pb}^{2+}$ ions in LuAP-based SCF with respect to YAP SCF due to preferable $\mathrm{Lu}-\mathrm{Pb}$ pair incorporation in comparison with incorporation of the $\mathrm{Y}-\mathrm{Pb}$ pair [21], supported also by the larger difference in the lattice misfit substrate-SCF in the case of LuAP SCF crystallization onto YAP substrates than in the case of homo-epitaxial growth of YAP:Ce SCF onto the same substrate.

The decay kinetics of the $\mathrm{Ce}^{3+}$ luminescence at 370-375 nm in YAP:Ce SCF (curves 1, 3) and LuAP:Ce SCF (curves 2, 4) under excitation by SR radiation in the $\mathrm{Ce}^{3+}$ absorption band at $295 \mathrm{~nm}$ (curves 1,2) and exciton range at 145-160 nm (curves 3, 4) at $300 \mathrm{~K}$ is shown in Fig. $4 \mathrm{~b}$. All the decay curves of the $\mathrm{Ce}^{3+}$ luminescence in these SCFs are visibly non-exponential and can be quantitatively characterized by an average decay time of 13.7 and $16.8 \mathrm{~ns}$, respectively, under excitation in the $\mathrm{Ce}^{3+}$ absorption band, and 22.75 and $22.4 \mathrm{~ns}$, respectively, under excitation in the exciton range of YAP and LuAP hosts (Table 1). We have also observed the visible acceleration of the decay time of the $\mathrm{Ce}^{3+}$ luminescence in YAP:Ce and LuAP:Ce SCF, grown from the 
PbO-based flux in comparison with that value of 16.2 and 18.1 ns in YAP:Ce and (YLu)AP:Ce SC counterpart (see also Table 1). Such an acceleration of the decay kinetics of the $\mathrm{Ce}^{3+}$ luminescence in YAP:Ce SCF scintillators, grown from the PbObased flux, can be caused by the energy transfer from the excited $\mathrm{Ce}^{3+}$ ions to some $\mathrm{Pb}^{2+}$-related centers, which have the excitation bands in the 350-370 nm range, well overlapped with $\mathrm{Ce}^{3+}$ emission band [24]. This energy transfer induces the losses of efficiency of $\mathrm{Ce}^{3+}$ emission which partly explain low LY of YAP:Ce and LuAG:Ce SCF scintillators, grown from the PbObased flux with respect to their SC analogues (Table 1).

The decay kinetics of the $\mathrm{Ce}^{3+}$ luminescence in the YAP:Ce and LuAP:Ce SCF measured at 370-375 nm under excitation in the exciton range possesses the fast components with an average decay time of 22.4-22.8 ns close to the lifetime of the $\mathrm{Ce}^{3+}$ luminescence as well as the slow emission component with a decay time in the hundred ns range related mainly to the intrinsic luminescence of $\mathrm{Pb}^{2+}$ ions, which partly overlapped with the $\mathrm{Ce}^{3+}$ emission band [24, 25].

Similarly to the situation with low LY of SCF based on the $(\mathrm{Lu}, \mathrm{Y}) \mathrm{SO}$ compounds, the problem with low $\mathrm{LY}$ of $\mathrm{Ce}^{3+}$ doped (Y,Lu)AP SCF can be eliminated using the co-doping of these SCF by $\mathrm{Tb}^{3+}$ ions. The $\mathrm{Tb}^{3+}$ ions also have significantly larger segregation coefficient (of about 0.7 [21]) in $(\mathrm{Y}, \mathrm{Lu}) \mathrm{AP}$ SCF then $\mathrm{Ce}^{3+}$ ions (of about 0.01) [25]; therefore the ratio of $\mathrm{Ce}+\mathrm{Tb}$ activators/ $\mathrm{Pb}$ impurity in these SCF can be significantly increased.

For investigation of the influence of $\mathrm{Tb}$ dopant on the luminescence and LY of Ce-doped SCF of perovskites, we have grown and investigated the luminescent properties of $\mathrm{Ce}, \mathrm{Tb}$ doped LuAP:Ce,Tb SCF with different $\mathrm{Tb}_{4} \mathrm{O}_{7}$ content in the $0.3-2.4 \%$ range. The CL spectra of LuAP:Ce,Tb SCF present the superposition of the broad fast $\mathrm{Ce}^{3+}$ luminescence in the UV range and the sharp-line slow emission of $\mathrm{Tb}^{3+}$ ions in the blue and green ranges, visible range, related to the ${ }^{5} \mathrm{D}_{3^{-}}$${ }^{7} \mathrm{~F}_{\mathrm{x}}$ and ${ }^{5} \mathrm{D}_{4}{ }^{7} \mathrm{~F}_{\mathrm{x}}$ transitions of $\mathrm{Tb}^{3+}$ ions (Fig.5). The blue emission of $\mathrm{Tb}^{3+}$ ions disappears with increasing the terbium concentration in MS due to the cross-relaxation transitions between the ${ }^{5} \mathrm{D}_{3}$ and ${ }^{5} \mathrm{D}_{4}$ radiative levels of $\mathrm{Tb}^{3+}$ ions (Fig.5).

In comparison with CL spectra of LuAP:Ce SCF (Fig.5, curve 1), the intensity of the $\mathrm{Ce}^{3+}$ luminescence in LuAP:Ce, Tb

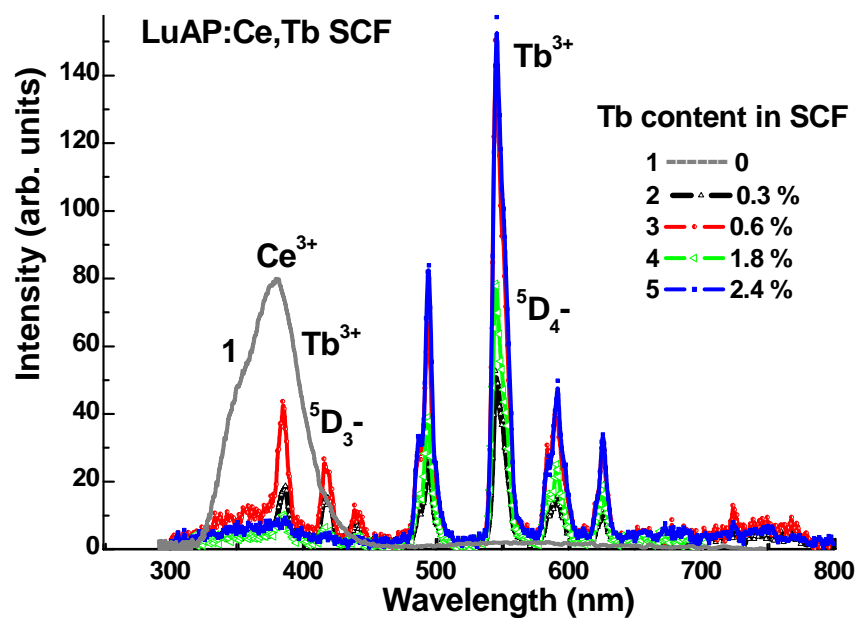

Fig.5. Normalized X-ray excited spectra of LuAP:Ce SCF (1) and LuAP:Ce,Tb SCF grown with different content of Tb activator in MS.
SCF (Fig.5, curves 2-5) is strongly decreased. This fact confirms the existence of the effective $\mathrm{Ce}^{3+} \rightarrow \mathrm{Tb}^{3+}$ energy transfer in LuAP:Ce,Tb SCF due to the overlap of the $\mathrm{Ce}^{3+}$ emission and the ${ }^{5} \mathrm{D}_{3-}{ }^{7} \mathrm{~F}_{6}$ transition of $\mathrm{Tb}^{3+}$ peaked $383 \mathrm{~nm}$. Recently such effective $\mathrm{Ce}^{3+} \rightarrow \mathrm{Tb}^{3+}$ energy transfer has been observed by some of us in TbAP:Ce SCF [21]. The $\mathrm{Tb}^{3+}$ codoping also leads to the decrease of scintillation efficiency of LuAP:Ce,Tb SCF, measured in a time interval of $0.5 \mu$ s (see Table 1) due to the decrease of the contribution of the fast $\mathrm{Ce}^{3+}$ luminescence. But under X-ray excitation the total light output of $\mathrm{Tb}^{3+}$ doped LuAP SCF in the visible range is very high (Table 1) due to strong contribution of the $\mathrm{Tb}^{3+}$ luminescence and effective Ce-Tb energy transfer. Namely, the LY of X-ray excited luminescence of LuAP:Ce,Tb SCF is comparable with the LY of LSO:Ce,Tb SCF and by 40-45\% larger than that for high-quality YAG:Ce standard SC sample (Table 1).

Thus, similarly to SCF of orthosilicates, the Ce-Tb co-doping is very effective for improvement of scintillation performance of the scintillating screens based on (YLu)AP perovskites under Xray excitation. Such type of screens also can simultaneously emit in the UV and green ranges (Fig.5). The contribution of emission in the mentioned ranges can be changed by the total $\mathrm{Tb}^{3+}$ content in MS and the ratio between the $\mathrm{Ce} / \mathrm{Tb}$ ions in SCF using different temperatures of their crystallization.

\section{LUMINESCENCE SPECTRA AND LIGHT YIELD OF SC DOPED (LU,Y) $)_{3} \mathrm{AL}_{5} \mathrm{O}_{12}$ SCF SCINTILLATORS}

Similarly to $\mathrm{Tb}^{3+}$ ions, the $\mathrm{Sc}^{3+}$ isoelectronic impurity in YAG and LuAG host has relatively high segregation coefficients ( 0.55 and 0.4 , respectively) [15]. This allows to readily achieving the optimum scandium doping for both SC and SCF of these garnets in the $0.75-1 \%$ range, at which the highest LY is observed (Table 1, Fig.6). Namely, at the optimum $\mathrm{Sc}^{3+}$ content of about 1 at. \% the LY of YAG:Sc and LuAG:Sc SC under $\alpha-$ particles excitation $\left(\mathrm{Pu}^{239}\right.$ source, $\left.5.15 \mathrm{MeV}\right)$ is comparable and reaches the values of about $70 \%$ of that for the best reference YAP:Ce crystal (see Table 1). The LY of LuAG:Sc SCF was less than that for $\mathrm{SC}$ analogues (up to $46-48.5 \%$ with respect to the reference YAP:Ce SC scintillator, Fig.6 and Table 1) due to the quenching influence of the $\mathrm{Pb}^{2+}$ flux related impurity [24, 28]. Nevertheless, the influence of $\mathrm{Pb}^{2+}$ contamination on the UV luminescence of $\mathrm{Sc}^{3+}$-based centers in $(\mathrm{Lu}, \mathrm{Y}) \mathrm{AG}$ SCF is not so significant as compared with other UV emitting dopants, namely

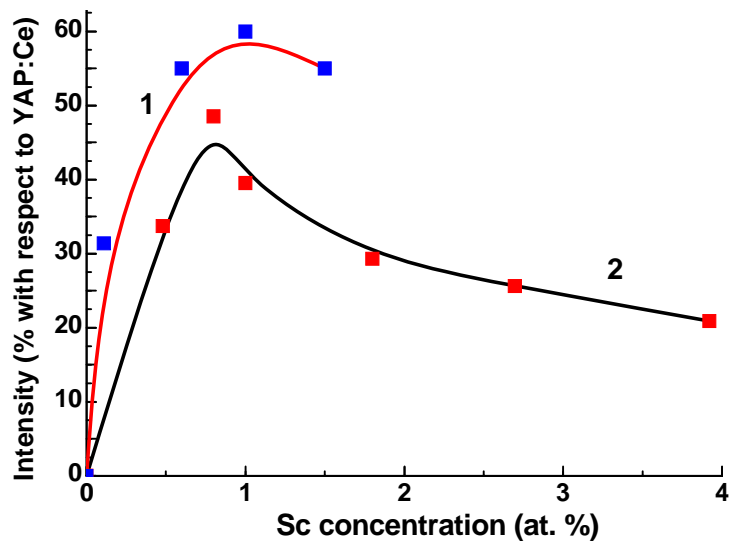

Fig.6. Dependence of LY on scandium concentration in series of LuAG:Sc SC (1) and SCF (2). 
the $\mathrm{Pr}^{3+}$ ions [32]. This allows the usage of $\mathrm{PbO}$-based flux for the growth of UV-emitting Sc-doped SCF scintillators based on the Sc-doped Lu-Y-Al garnets with relatively high LY.

In our previous work [15, 33-34] we have found that in Scdoped aluminium garnets the formation of two type of emission centers $\left(\mathrm{Sc}_{\mathrm{Y}, \mathrm{Lu}}\right.$ and $\left.\mathrm{Sc}_{\mathrm{Al}}\right)$ takes place which contributes to the intensive UV luminescence of these compounds and compete in the processes of energy transfer. In this work, we show that the emission spectrum (Fig.7a) and decay kinetics (Fig.7b) of LuAG:Sc SC and SCF can be effectively tuned by changing the Sc content and distribution of scandium ions in dodecahedral \{c\}- and octahedral (a)- sites of garnet lattice. Namely, the different substitution of $\mathrm{Sc}^{3+}$ ions for the $\mathrm{Al}^{3+}$ and $\mathrm{Lu}^{3+}$ cations in $\{c\}$-and (a)-sites, respectively, as well as the formation of the dimer $\mathrm{Sc}_{\mathrm{Al}}-\mathrm{Sc}_{\mathrm{Al}}$ or $\mathrm{Sc}_{\mathrm{Al}}-\mathrm{Sc}_{\mathrm{Lu}}$ centers [33-35] can explain the complex dependence of the LY (Fig.6) and positions of the UV emission band of LuAG:Sc SCF (Fig.7a) on the total Sc content.

We have also performed investigation of the dependence of luminescence decay kinetics of LuAG:Sc SCF on scandium content in these films under excitation by pulsed SR in the exciton range of LuAG host (Fig.7b). The measured decay curve presents the superposition of the luminescence of both
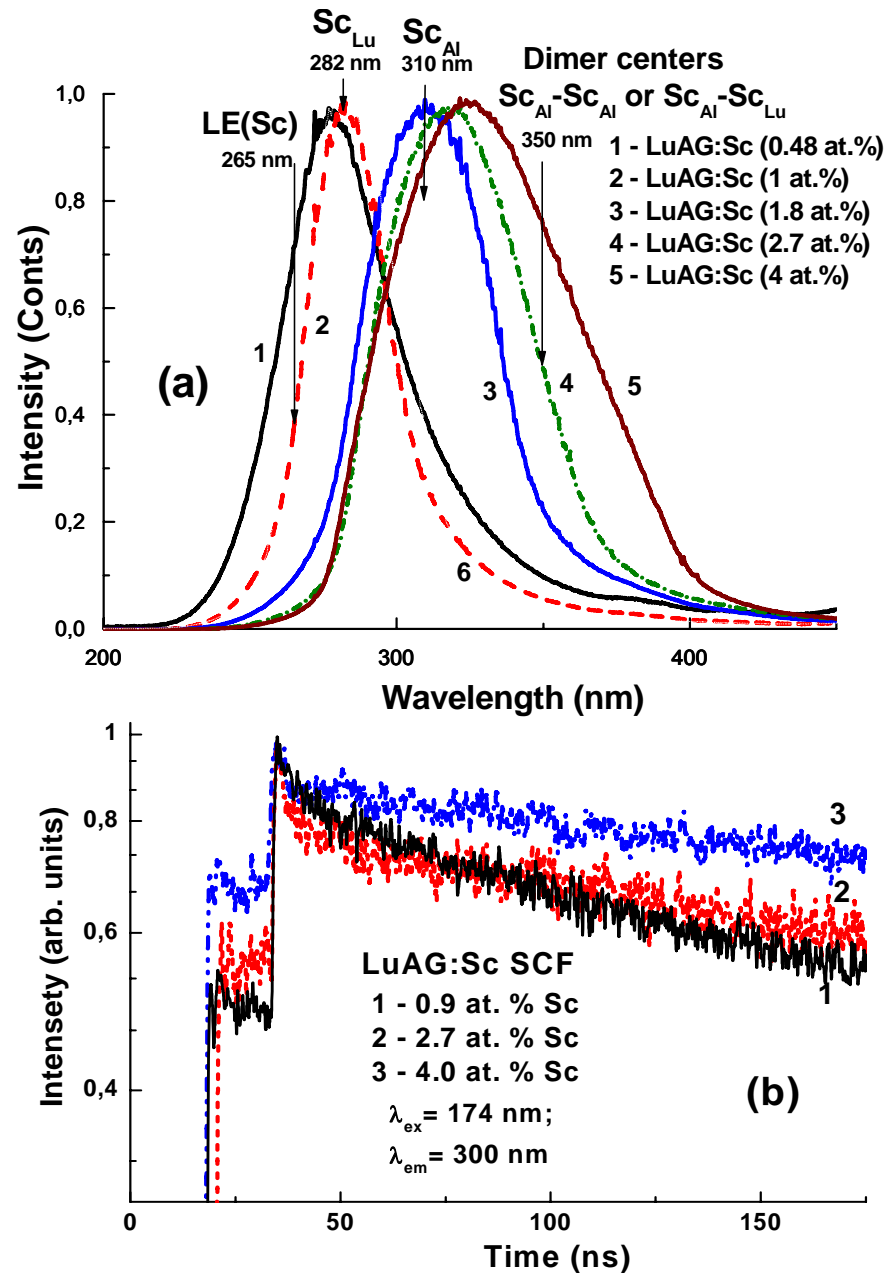

Fig.7 Normalized CL spectra at $300 \mathrm{~K}$ of LuAG:Sc SCF with different scandium content in the $0.48-4$ at. $\%$ range. The arrows indicate the positions of Sc related luminescence bands $[15,38]$. (b)- decay kinetics of the luminescence of Sc-related centers at $330 \mathrm{~nm}$ under excitation by SR with $\lambda_{\mathrm{ex}}=$ $174 \mathrm{~nm}$ at $300 \mathrm{~K}$ in LuAG:Sc SCF with $\mathrm{Sc}^{3+}$ content of 0.9 at.\% (1); 2.7 at.\% (2) and 4.0 at.\% (3), respectively.
Table 2. Dependence of decay time of the luminescence at $300 \mathrm{~nm}$ (at 280 $\mathrm{nm}$ for sample No $3^{*}$ ) on the total Sc content in the LuAG:Sc SCF. Excitation by SR at $174 \mathrm{~nm}$ in exciton range of LuAG host (see Fig.7b).

\begin{tabular}{|c|c|c|c|c|c|}
\hline No & Sc content, at. $\%$ & $\mathbf{A}_{\mathbf{1}}$ & $\boldsymbol{\tau}_{\mathbf{1}}, \mathbf{n s}$ & $\mathbf{A}_{\mathbf{2}}$ & $\boldsymbol{\tau}_{\mathbf{2}}, \mathbf{n s}$ \\
\hline 1 & 4.0 & - & - & 0.73 & 617 \\
\hline 2 & 2.7 & 0.192 & 2.85 & 0.65 & 450 \\
\hline $3^{*}$ & 1.9 & 0.18 & 2.1 & 0.6 & 450 \\
\hline 4 & 0.9 & 0.135 & 9.7 & 0.70 & 299 \\
\hline
\end{tabular}

$\mathrm{Sc}_{\mathrm{Al}}$ and $\mathrm{Sc}_{\mathrm{Lu}}$ centers. We note that the decay kinetics of the emission of these centers is typical for the luminescence of excitons bound with isoelectronic impurities [33, 34] and present the superposition of the fast component with the decay time in the range of few ns and the main slow component with the decay time in the hundred ns range.

As can be seen from Fig. $7 \mathrm{~b}$ and Table 2, the decay kinetics of the luminescence of LuAG:Sc is systematically slowed when the concentration of $\mathrm{Sc}$ is growing from 0.9 to 4.0 at. $\%$. For this reason, the optimal Sc concentration in LuAG:Sc SCF and SC should be chosen approximately at 1 at. \%, at which the faster decay kinetics (Fig.7b) and the highest LY (Fig.6) of the $\mathrm{Sc}^{3+}$ luminescence in the main band peaked around of $280 \mathrm{~nm}$ are obtained.

\section{CONCLUSIONS}

We have reviewed our R\&D works on several types of single crystalline film (SCF) scintillators grown by the liquid phase epitaxy (LPE) method:

1) Ce doped $\mathrm{SCF}$ of $(\mathrm{LuY})_{2} \mathrm{SiO}_{5}$ silicates and $(\mathrm{LuY}) \mathrm{AlO}_{3}$ perovskites, where the fast and intensive $5 \mathrm{~d}-4 \mathrm{f}$ luminescence of $\mathrm{Ce}^{3+}$ ions occurs in the $325-600 \mathrm{~nm}$ and $325-450 \mathrm{~nm}$ ranges with main peak at $430 \mathrm{~nm}$ and $370-380 \mathrm{~nm}$, respectively and corresponding decay time values are of 16-20 ns and 22-23 ns.

2) $\mathrm{Ce}$ and $\mathrm{Tb}$ co-doped $\mathrm{SCF}$ of $(\mathrm{LuY})_{2} \mathrm{SiO}_{5}$ silicates and ( $\mathrm{LuY}) \mathrm{AlO}_{3}$ perovskites with simultaneous emission in the UV and green ranges. The contribution of the $\mathrm{Ce}^{3+}$ emission in the $\mathrm{UV}$ and blue ranges in the $\mathrm{Ce}, \mathrm{Tb}$ doped SCF of the mentioned compounds can be changed by the ratio between the content of $\mathrm{Ce}$ and $\mathrm{Tb}$ ions in these SCF defined by growth temperature.

We have found significant negative influence of the $\mathrm{Pb}^{2+}$ flux impurity on the UV luminescence of $\mathrm{Ce}^{3+}$ ions in SCF of silicates and perovskites. $\mathrm{Pb}$ contamination is the main reason for significantly lower LY of Ce-doped (Lu,Y)SO and (Lu,Y)AP SCF scintillators in comparison with single crystal counterparts (by 4-5.5 and 4-7.5 times, respectively).

The problem with low LY of $\mathrm{Ce}^{3+}$ doped $(\mathrm{Lu}, \mathrm{Y}) \mathrm{SO}$ and (Y,Lu)AP SCF can be partly eliminated by using the $\mathrm{Tb}^{3+}$ codoping with large segregation coefficient (0.6-0.7) in these SCFs. Due to the strong contribution of the $\mathrm{Tb}^{3+}$ luminescence and the effective $\mathrm{Ce}-\mathrm{Tb}$ energy transfer, the total LY of the X-ray excited luminescence of Ce,Tb doped LSO and LuAP SCFs is by 40-45 $\%$ larger than that for high-quality YAG:Ce SCF sample (Table 1).

3) $\mathrm{Sc}^{3+}$ doped $\mathrm{SCF}$ of $(\mathrm{Lu}, \mathrm{Y})_{3} \mathrm{Al}_{5} \mathrm{O}_{12}$ garnets emitting in the 225-425 $\mathrm{nm}$ range due to formation of $\mathrm{Sc}_{\mathrm{Y}, \mathrm{Lu}}$ and $\mathrm{Sc}_{\mathrm{Al}}$ emission centers with the decay time of their luminescence in the several hundred ns range.

We note that the influence of $\mathrm{Pb}^{2+}$ impurity on the UV luminescence of $\mathrm{Sc}^{3+}$-based centers is not so significant which allows the usage of PbO-based flux for producing such type of SCF scintillators with high LY. 
Future development of blue-UV scintillators based on $\mathrm{Ce}^{3+}$ doped SCF of silicates and perovskites can be also performed by using alternative lead-free fluxes for their crystallization, e.g. the $\mathrm{BaO}-\mathrm{B}_{2} \mathrm{O}_{3}-\mathrm{BaF}_{2}$ flux was used by us for the growth of YAP:Ce SCF [25]. However, using the BaO-based fluxes limits the possibility of hetero-epitaxial growth crystallization of Lu-based compounds on cheaper Y-based substrates. For this reason, the crystallization of SCF of LSO and LuAP onto undoped YSO and YAP substrates from $\mathrm{BaO}$-based flux has not been performed yet.

\section{REFERENCES}

[1] B. Ferrand, B. Chambaz, M. Couchaud, "Liquid phase epitaxy: A versatile technique for the development of miniature optical components in single crystal dielectric media", Optical Materials, vol.11, pp.101-114, 1999.

[2] J.M. Robertson, M.V. van Tol, "Epitaxially grown monocrystalline garnet cathode-ray tube phosphor screens", Appl .Phys. Lett., vol.37, №5, pp.471-472, 1980.

[3] J.M. Robertson, M.W. van Tol, W.H. Smits, J.P.H. Heynen "Colourshift of the $\mathrm{Ce}^{3+}$ emission in monocrystalline epitaxial growth garnet layers ", Philips Journal of Research, vol.36, №.1, pp.15-30, 1981.

[4] J.M. Robertson, M.V. van Tol, "Cathodoluminescent garnet layers", Thin Solid Films, vol.114, № 1-2, pp.221-240, 1984.

[5] Z.D. Hrytskiv, Y. Zorenko, V. Gorbenko, A.D. Pedan, V.I. Shkliarskyi. "Single crystalline film screens for cathode-ray tubes: New life of television scanning optical microscopy". Radiation Measurements. 2007. V.42, № 4-5. P. 933-936.

[6] Yu. V. Zorenko, S. S. Novosad, M. V. Pashkovskii, A. B. Lyskovich, V. G. Savitskii, M. M. Batenchuk, P. S. Malyutenkov, N. I. Patsagan, I. V. Nazar, V. I. Gorbenko, "Epitaxial structures of garnets as scintillation detectors of ionizing radiation", Journal of Applied Spectroscopy, vol. 52, № 6, pp.645-649, 1990.

[7] M. Globus, B. Grinyov, M. Ratner, V. Tarasov, V. Lyubinskiy, Y. Vydai, A. Ananenko, Y. Zorenko, V. Gorbenko, I. Konstankevych, "New Type of Scintillation Detectors for Biological, Medical, and Radiation Monitoring Applications", IEEE Transact. on Nucl. Sci. vol.51, No.3, pp.1297-1303, 2004.

[8] M. Globus, B. Grinyov, "Non-organic scintillators. New and traditional materials. Kharkiv: Akta, 2000.

[9] Yu. Zorenko, V. Gorbenko, I. Konstankevych, B. Grinev, M. Globus, "Scintillation properties of $\mathrm{Lu}_{3} \mathrm{Al}_{5} \mathrm{O}_{12}$ :Ce single crystalline films," Nuclear Instr. Meth. Phys. Res. A., vol.486, pp.309-314, 2002.

[10] A. Koch, C. Raven, P. Spanne, A. Snigirev, "X-ray imaging with submicrometer resolution employing transparent luminescent screens," $J$. Opt. Soc. Am., vol. A 15, pp.1940-1951, 1998.

[11] A. Koch, F. Peyrin, P. Heurtier, B. Chambaz, B. Ferrand, W. Ludwig, M. Couchaud, "An x-ray camera for computed microtomography of biological samples with micrometer resolution using $\mathrm{Lu}_{3} \mathrm{Al}_{5} \mathrm{O}_{12}$ and $\mathrm{Y}_{3} \mathrm{Al}_{5} \mathrm{O}_{12}$ scintillators", Proc SPIE, vol. 3659, pp.170-179, 1999.

[12] T. Martin, A. Koch "Recent development in X-ray imaging with micrometer spatial resolution", Journal of Synchrotron Radiation, vol. 13, pp.180-194, 2006.

[13] T. Martin, P-A. Douissard, M. Couchaud, A. Cecilia, T. Baumbach, K. Dupré, A. Rack "LSO-Based Single Crystal Film Scintillator for Synchrotron-Based Hard X-Ray Micro-Imaging," IEEE Transaction on Nuclear Science, vol. 56, pp. 1412 - 1418, 2009.

[14] P.-A. Douissard, A. Cecilia, T. Martin, V. Chevalier, M. Couchaud, T. Baumbach, K. Dupré, M. Kühbacher and A. Rack, "A novel epitaxially grown LSO-based thin-film scintillator for micro-imaging using hard synchrotron radiation", J. Synchrotron Rad. (2010). 17, 571-583

[15] Zorenko Yu., Gorbenko V, Nikl M, Mares J A, Martin T, Douissard P-A „Development of novel UV emitting single crystalline film scintillators“ IEEE Trans. Nucl. Sci., vol.57, pp. 1335-1342, 2010.

[16] Yu. Zorenko, V. Gorbenko, I. Konstankevych, A. Voloshinovskii, G. Stryganyuk, V. Mikhailin, V. Kolobanov, D. Spassky, "Single-crystalline films of Ce-doped YAG and LuAG phosphors: advantages over bulk crystals analogues", Journal of Luminescence, vol.114, № 4, pp.85-94, 2005.

[17] Y. Zorenko, V. Gorbenko, E. Mihokova, M. Nikl, K. Nejezchleb, A. Vedda, V. Kolobanov, D. Spassky, "Single crystalline film scintillators based on Ce- and Pr-doped aluminium garnets, Radiation Measurements, vol.42, pp.521-527, 2007.

[18] P. Prusa, T. Cechak, J. A. Mares, M. Nikl, Yu. V. Zorenko, V. I. Gorbenko, J. Tous, K. Blaze, "The $\alpha$-particle excited scintillation response of the liquid phase epitaxy grown LuAG:Ce thin films", Applied Physics Letters, vol.2, No 1, pp.1-3, 2008.

[19] Yu. Zorenko, M. Nikl, V. Gorbenko, V. Savchyn, T. Voznyak, R. Kucerkova, O. Sidletskiy, B. Grynyov, A. Fedorov. "Growth and luminescent properties of $\mathrm{Lu}_{2} \mathrm{SiO}_{5}$ and $\mathrm{Lu}_{2} \mathrm{SiO}_{5}$ :Ce single crystalline films", Optical Materials, vol. 33, No 6, pp.846-852, 2011.

[20] Yu. Zorenko, V. Gorbenko, V. Savchyn, T. Voznyak, B. Grinyov, O. Sidletskiy, D. Kurtsev, A. Fedorov, V. Baumer, M. Nikl, J.A. Mares, A. Beitlerova, M. Kucera. "Growth and luminescent properties of $\mathrm{Lu}_{2} \mathrm{SiO}_{5}$ : $\mathrm{Ce}$ and $\left(\mathrm{Lu}_{1-\mathrm{x}} \mathrm{Gd}_{\mathrm{x}}\right)_{2} \mathrm{SiO}_{5}$ :Ce single crystalline films", Journal of Crystal Growth, vol. 337, pp.72-80, 2011.

[21] Y. Zorenko, V. Gorbenko, "Growth and luminescent properties of single crystalline films of $\mathrm{RAlO}_{3}(\mathrm{R}=\mathrm{Lu}, \mathrm{Lu}-\mathrm{Y}, \mathrm{Y}, \mathrm{Tb})$ perovskites", Physics of Solid State, vol.51, No.9, pp.1800-1808, 2009.

[22] Y. Zorenko, V. Gorbenko, I. Konstankevych, T. Voznjak, V. Savchyn, M. Nikl, J.A. Mares, K. Nejezchleb, V. Mikhailin, V. Kolobanov, D. Spassky, "Peculiarities of luminescence and scintillation properties of YAP:Ce and LuAP:Ce single crystals and single crystalline films," Radiation Measurements, vol.42, pp.528-532, 2007.

[23] Yu. Zorenko, V. Gorbenko, T. Voznyak, V. Mikhailin, V. Kolobanov, D. Spassky, and M. Nikl "Intrinsic and $\mathrm{Ce}^{3+}$-Related Luminescence in Single Crystalline Films and Single Crystals of LuAP and LuAP:Ce Perovskites", IEEE Transaction on Nuclear Science. vol.55, No 3, pp. 1192-1196, 2008.

[24] V. Babin, V. Bichevin, V. Gorbenko, A. Makhov, E. Mihokova, M. Nikl, A. Vedda, S. Zazubovich, and Yu. Zorenko, "Luminescence of dimer lead centers in aluminium perovskites and garnets", Phys. Status Solidi (b), vol.246, No. 6, pp.1318-1326, 2009.

[25] Y. Zorenko, V. Gorbenko, V. Savchyn, T. Voznyak, M. Nikl, J.A. Mares, A. Beitlerova, R. Kucerkova, "The luminescent and scintillation properties of YAP and YAP:Ce single crystalline films grown by liquid phase epitaxy from BaO-based flux," Phys. Status Solidi A, Vol. 206, pp.2586-2592, 2009.

[26] Y. Zorenko, V. Gorbenko "Growth peculiarities of the $\mathrm{R}_{3} \mathrm{Al}_{5} \mathrm{O}_{12}(\mathrm{R}=\mathrm{Lu}$, $\mathrm{Yb}, \mathrm{Tb}, \mathrm{Eu}-\mathrm{Y}$ ) single crystalline film phosphors by Liquid Phase Epitaxy”, Radiation Measurements, vol. 42, № 4-5, pp. 907-910, 2007.

[27] Yu. Zorenko, A. Voloshinovskii, V. Savchyn, T. Vozniak, M. Nikl, K. Nejezchleb, V. Mikhailin, V. Kolobanov, D. Spassky, "Exciton and antisite defect-related luminescence in $\mathrm{Lu}_{3} \mathrm{Al}_{5} \mathrm{O}_{12}$ and $\mathrm{Y}_{3} \mathrm{Al}_{5} \mathrm{O}_{12}$ garnets", Phys. Stat. Sol. (b), vol. 244, pp.2180-2189, 2007.

[28] V. Babin, V. Gorbenko, A. Makhov, J.A. Mares, M. Nikl, S. Zazubovich, Yu. Zorenko. "Luminescence characteristics of $\mathrm{Pb}^{2+}$ centers in undoped and $\mathrm{Ce}^{3+}$-doped $\mathrm{Lu}_{3} \mathrm{Al}_{5} \mathrm{O}_{12}$ single crystalline films and $\mathrm{Pb}^{2+} \rightarrow \mathrm{Ce}^{3+}$ energy transfer processes," Journal of Luminescence, vol.127, No2, pp.384-390, 2007.

[29] http://abulafia.mt.ic.ac.uk/shannon/radius.php.

[30] G. Ren, L. Qin L, S. Lu, H. Li "Scintillation characteristics of lutetium oxyorthosilicate“, Nucl. Instr. Meth. Phys. Res. A., vol.531, pp.560-565, 2004.

[31] H. Feng, V. Jary, E. Mihokova, D. Ding, M. Nikl, G. Ren, H. Li, S. Pan, A. Beitlerova, R. Kucerkova. „Influence of yttrium content on the $\mathrm{Ce}_{\mathrm{Lu}}$ and $\mathrm{Ce}_{\mathrm{Lu} 2}$ luminescence characteristics in $\left(\mathrm{Lu}_{1-x} \mathrm{Y}_{x}\right)_{2} \mathrm{SiO}_{5}$ : $\mathrm{Ce}$ single crystals", J. Appl. Physics, vol.108, pp.033519-033525, 2010.

[32] V. Gorbenko, Yu. Zorenko, V. Savchyn, T. Zorenko, A. Pedan, V. Shkliarskyi. "Growth and luminescence properties of $\mathrm{Pr}^{3+}$-doped single crystalline films of garnets and perovskites," Radiation Measurements, vol. 45, pp. 461-464, 2010.

[33] Yu. Zorenko, V. Gorbenko, A. Voloshinovskii, G. Stryganyuk, S. Nedilko, V. Degoda, O. Chykova, "Luminescence of Sc-related centers in single crystalline films of $\mathrm{Lu}_{3} \mathrm{Al}_{5} \mathrm{O}_{12}$ garnet", Phys. stat. sol. (c), vol. V.2, №1, pp.105-108, 2005.

[34] Yu.V. Zorenko, "Luminescence of $\mathrm{La}^{3+}$ and $\mathrm{Sc}^{3+}$ isoelectronic impurities in $\mathrm{Lu}_{3} \mathrm{Al}_{5} \mathrm{O}_{12}$ single crystalline films," Optics and Spectroscopy, vol.100, pp.572-580, 2006.

[35] Ja. A. Valbis, L.G. Volzhenskaja, Yu.G. Dubov, Yu.V. Zorenko, I.V. Nazar, N.I. Patszagan. "Luminescence centers in single crystalline compounds of yttrium-aluminium garnet doped by scandium isoelectronic impurity,” Optics and Spectroscopy, vol.63, №5, pp.1058-1063, 1987. 